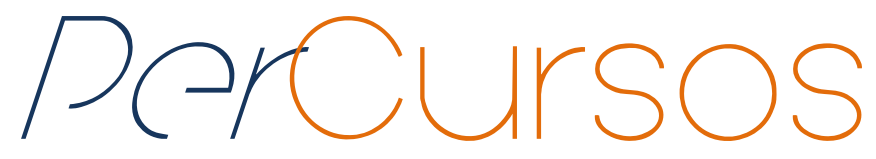

\title{
Arte e descolonização como um mecanismo de defesa na obra de Grada Kilomba
}

\section{Resumo}

Apresentação da obra Memórias da Plantação: episódios de racismo cotidiano e da série audiovisual Illusions, especialmente, "Narcissus and Echo", criados por Grada Kilomba. A artista, filósofa e psicanalista, ilustra as operações estético-sensíveis do seu corpus teórico, através de um testemunho crítico sobre a história e epistemologia do racismo denominado racismo ontológico. Neste artigo, o trabalho subjetivo atua em diferentes campos, de forma interdisciplinar: na descolonização do conhecimento; na interseccionalidade entre questões de classe, gênero e raça; como também, no desejo de constituição de um sujeito da negritude. Sendo assim, este artigo pretende traçar um panorama argumentativo que destrinche o que é o racismo epistemológico e como ele afeta o cotidiano nas instituições e na psique social. Finalmente, através da obra e do pensamento de Grada Kilomba, perguntar como podemos operar novos meios de reparação histórica e criar novas sensibilidades, compondo assim um novo sujeito, ou ainda, uma existência além da redução ao silêncio, ilustrado pela máscara de Anastácia. São, portanto, temáticas diferentes que se entrecruzam para tentar dar conta da realidade social, que nos afeta no campo político, sensível e sentimental. Por isso, de antemão, a teoria se revela uma prática do pensamento ativista, como também, a arte se revela uma forma de pensar a vida e vice-versa, compondo uma ética que descoloniza o pensamento, a arte, a memória e que emancipa ao produzir outras maneiras de expressão do ser.

Palavras-chave: Descolonização estética. Afrossensibilidade. Racismo epistemológico. Feminismo intersecciconal.

\author{
Raisa Inocencio Ferreira Lima \\ Mestrado em Master Erasmus \\ Mundus Europhilosophie pela \\ Université de Toulouse II - Le \\ Mirail, UTM, França. \\ Doutoranda em Filosofia na \\ Université Toulouse Jean Jaurès, \\ UT2J, França. \\ França \\ inocencio.raisa@gmail.com
}

\author{
Para citar este artigo: \\ LIMA, Raisa Inocencio Ferreira. Arte e descolonização como um mecanismo de defesa na obra de Grada \\ Kilomba. Revista PerCursos, Florianópolis, v. 20, n.44, p. 11 - 34, set./dez. 2019.
}

DOI: $10.5965 / 1984724620442019011$

http://dx.doi.org/10.5965/1984724620442019011 


\title{
Art and institutional decolonization as a defense mechanism in the work of Grada Kilomba
}

\begin{abstract}
Presentation of the work Plantation memories: episodes of everyday racism and the audiovisual series Illusions, especially "Narcissus and Echo", created by Grada Kilomba. The artist, philosopher and psychoanalyst illustrates the aesthetic-sensitive operations of her theoretical corpus through a critical testimony about the history and epistemology of racism - called ontological racism in this article - and the subjective work in different fields of interdisciplinary form: the decolonization of knowledge; the intersectionality between issues of class, gender and race; as well as the desire for constitution of the subject of blackness. Thus, this paper intends to draw an argumentative panorama that distinguishes what epistemological racism is and how it affects daily life, institutions and the social psyche. Finally, through the work and thought of Grada Kilomba, this article intends to ask how we can operate new means of historical reparation and creation of new sensibilities, thus composing a new subject, or even an existence beyond the reduction to silence, illustrated by the mask of Anastacia. They are, therefore, different themes that intersect to try to account for social reality, which affects us in the political, sensitive and sentimental field. That is why, beforehand, theory reveals itself as a practice of activist thought, as well as art reveals itself as a way of thinking about life and vice versa, composing an ethic that decolonizes thought, art, memory and that emancipates, that produces other ways of expression of being.
\end{abstract}

Keywords: Aesthetic decolonization. Afrosensitivity. Epistemological racism. Intersectional feminism. 


\author{
"As ferramentas do senhor de engenho não \\ destruirão jamais a casa grande."1
}

Este artigo traça uma análise sobre como se opera a descolonização do saber através da apresentação do corpo estético-político da artista, psicanalista e filósofa Grada Kilomba com o livro Memórias da Plantação: episódios de racismo cotidiano ${ }^{2}$ e suas composições artísticas mais recentes na série Illusions, especificamente a primeira, chamada Narcissus and Echo, a qual foi exposta na 31 ${ }^{\text {a }}$ Bienal de São Paulo no ano de 2014, e, mais recentemente, na Pinacoteca do Estado de São Paulo, em 2019.

O livro foi publicado em 2010, no qual conta o percurso de uma teoria interdisciplinar que destaca a questão do sujeito e do seu lugar no mundo, ou, por assim dizer, questiona a constituição do sujeito diante da história racista do pensamento. Sobretudo, no contexto artístico e institucional nos parece relevante estudá-lo, compondo tanto uma análise textual, mas também, uma sensibilidade a partir de sua mais recente instalação visual Illusions vol 1.: Narcissus and Echo ${ }^{3}$. Trata-se de um caminho conceitual e sensível efetivo no combate ao racismo e, no caso filosófico, o racismo estético-ontológico-epistemológico.

De antemão, interpretar o seu trabalho parte do rompimento de paradigmas e metodologias, que não separam os campos do conhecimento - por exemplo: a psicologia, a arte e a filosofia - entre si, mas, sobretudo, faz um traço em si, como a própria prática da pesquisa interdisciplinar. O que Kilomba propõe é considerar o sujeito e a subjetividade como uma série de movimentos conceituais e performativos, vendo a própria realidade como a constituição do sujeito e do desejo de ser sujeito, que lhe permite existir e viver. Dessa forma, desenvolve uma crítica e uma resistência à história,

\footnotetext{
1 LORDE, Audre. Sister Outsider: essays and speeches. Crossing Press. 1984. Tradução livre.

2 KILOMBA, Grada. Memorias da Plantação: episódios de Racismo Quotidiano. Lisboa : Orfeo Negro, 2019. Edição utilizada para este artigo: Plantation memories : Episodes of everyday racism. Berlin: UNRAST, 2010. Acesso em 2019. https://archive.org/details/PlantationMemoriesEpisodesGradaKilomba. poética" à Pinacoteca de São Paulo. https://youtu.be/ovSKrDLs9Ro.
} 
não findada, da colonização e da escravidão, que persiste em relatos pessoais que comprovam também o racismo institucional.

Dito de outra maneira, este artigo considera relevante uma composição de diferentes perspectivas para abordar o mesmo assunto, nomeadamente, a descolonização político-estético-sensível. Esse olhar possível ressaltar a relevância do trabalho de Kilomba, como resultado de uma política "artivista" de cura, sobretudo, da ferida colonial, mas também da implementação do projeto político da reparação histórico-existencial, social e interpessoal.

Kilomba, por si só, opera essa visada interdisciplinar, que não é categorizada em uma única etiqueta. Pelo contrário, a sua presença é dita e construída através de uma dança conceitual, que passa da psicanálise à mitologia, da mitologia à dança, e da dança, mais uma vez, ao pensamento. Essa é a sua versatilidade que, uma vez implementada, permite a criação de novas epistemologias descolonizantes.

Tais epistemologias descolonizantes consistem em desmontar a máquina colonial, a partir da singularidade de uma experiência vivida, da emancipação e da restauração da chamada história "ocidental" - a mesma que utilizou o racismo ontológico e praticou a exclusão do pensamento como instrumento de poder e dominação.

Em seguida, parece igualmente relevante notar que já existem leituras e análises, como as da filósofa Djamila Ribeiro ${ }^{4}$ que, por sua vez, estabelece uma análise consistente baseada no afrofeminismo americano e; no que tange a produção intelectual brasileira, das autoras Sueli Carneiro e Maria Aparecida Bento. Ribeiro apresenta uma constelação conceitual crítica ao racismo epistemológico, compreendendo no que ele consiste e como é possível rompê-lo. Por isso, o primeiro passo conceitual é analisar a definição do racismo e do racismo epistemológico, para em seguida, apresentar o livro e as obras visuais de Kilomba.

\footnotetext{
${ }^{4}$ RIBEIRO, Djamila. Lugar de Fala. Polen, São Paulo. 2019.
} 


\section{Definindo o racismo}

A primeira questão que se coloca é como se dá a operação do racismo no âmbito do pensamento e da prática do pensamento sobre as diferentes disciplinas, artísticas e psicanalíticas, ou seja, a definição mesma do que se trata o racismo. Ao centrar-nos no corpo teórico de Kilomba, podemos ver de antemão uma influência em Franz Fanon e no afrofeminismo americano, notadamente, na obra de bell hooks e Patricia Hill Collins. Em seu livro Memórias da Plantação, Kilomba primeiro define o que é o racismo e quais são os efeitos sintomáticos oriundos do trauma colonial na subjetividade negra, para depois criar um estatuto existencial.

Estatuto existencial crítico ao projeto de supremacia branca, que historicamente nomeia a negritude e o ser negro como o “Outro". Esses sujeitos são visualizados como um outro diferente do que é o "normal” e toda a reprodução e tentativa de assimilação ao que é considerado igual acaba sendo visto e performado como uma farsa, ou um falso simulacro da branquitude.

Esses gestos performáticos dão, consequentemente, origem a uma série traumática de efeitos, que vão desde a aniquilação do eu até uma banalização de situações cotidianas de racismo. Sendo assim, podemos dar uma definição primária do que é o racismo: "O racismo é uma realidade violenta. Tem sido central na construção da política europeia durante séculos, a começar pelos projetos europeus da escravatura, da colonização e da atual fortaleza europeia." (KILOMBA, 2010, p. 40).

Essa construção racista do "ser" e do "aparecer o ser" ou, dito de outra maneira, do ser "Branco" e do ser "Outro", é aplicada durante uma série de operações discursivas, as quais consistem, por um lado, na identificação - assimilação, integração, simulacro - e pelo outro na diferenciação. O que faz essa diferenciação é uma inferiorização que restringe o poder de ação, portanto, pessoas racializadas e negras são assimiladas de forma a perceber o branco como superior e perfeito. Segundo Kilomba, primeiro, do ponto de vista da branquitude, existem três formas características de definir o racismo. $\mathrm{O}$ racismo é, então, o resultado de uma simultaneidade de fatores de valor-vetor aplicados (KILOMBA, 2010, p. 42). A primeira é a construção da diferença, em que ele vê o "Outro" 
como diferente, exceto quando Kilomba (2010, p. 42) questiona, "quem é diferente de quem?" A única diferença que ela expõe é o poder da norma, o projeto da supremacia da branquitude detém a norma "verdadeira" como própria, portanto, pertence a ela o poder de agir e de pensar.

Essas diferentes construções estão inseparavelmente ligadas a uma hierarquia de valores, pois

Não só o indivíduo é visto como um 'diferente', mas também esta diferença é articulada através do estigma, da desonra e da inferioridade. Tais valores hierárquicos implicam um processo de naturalização, uma vez que são aplicados a todos os membros do mesmo grupo que são vistos como "o problemático", "o difícil”, “o perigoso", "o preguiçoso", “o exótico", "o colorido" e "o incomum”. (KILOMBA, 2010, p. 42)

Finalmente, estes dois processos, de identificação e diferenciação, são acompanhados por um terceiro: o poder. O poder histórico, econômico, social ou político manifesta-se numa luta de narrativas pela dominação em dimensões estruturais, como a educação, a saúde, a política de representação identitária e os meios de comunicação.

"Racismo é supremacia branca" (KILOMBA, 2010, p. 42). Em todo o caso, para Kilomba, a questão já não é tornar-se o centro hierárquico do discurso (2010, p. 32-36), mas uma alternativa de emancipação e produção de conhecimento:

Eu escrevo da periferia, não do centro. Este é também o lugar de onde estou teorizando, pois coloco meu discurso dentro da minha realidade. [...] Um discurso que é tão político quanto pessoal e poético, como os escritos de Fanon "para trazer à tona uma oportunidade de produção alternativa de conhecimento emancipatório". (KILOMBA, 2010, p.32).

\section{O racismo epistemológico e a leitura de Djamila Ribeiro}

Ao longo deste texto serão desenvolvidos três conceitos que conduzem a uma compreensão do racismo, dada a primeira definição de Grada Kilomba. A primeira 
apresentada será a leitura de Djamila Ribeiro no seu livro Lugar de Fala, que usa como referência o texto de Grada Kilomba com a noção esclarecedora de epistemicídio5; e finalmente, o conceito de interseccionalidade ${ }^{6}$ que, ao dar diferentes graus de compreensão sobre a opressão racial, de classe e de gênero, complementa de forma introdutória os fundamentos da obra de Grada Kilomba e a constituição de uma expressão ontológica e epistemológica negra.

Djamila Ribeiro, tal como Grada Kilomba, faz parte desta geração de filósofas negras que não separam a vida intelectual da vida militante, que imaginam uma prática encarnada do pensamento e que ligam o seu trabalho a um objetivo político-social. Ribeiro é frequentemente convidada a participar de diversos tipos de encontros, para revelar e desconstruir ambiguidades sociais; por exemplo, o fato de que a população negra no Brasil nem sempre tem o mesmo acesso que a população branca a certos lugares, como a televisão e a opinião pública, pois ainda é associada à escravidão e à inferioridade.

A noção do lugar de fala se conecta diretamente com o que Grada Kilomba propõe, justamente porque não há uma cultura de legitimação, uma cultura que possa efetivamente romper com toda a pirâmide social, hierarquizada segundo uma prática discursiva e relacional de poder branco, masculino e patriarcal. Fato que marca a história do racismo desde a escravidão, como bem considerado por Spivak que apresenta, no seu livro Pode um subalterno falar?, uma violência à epistemologia considerada como periférica, no sentido de que ela deve então ser criada, definida e descentralizada do norte anglo-europeu.

Se analisarmos o que Ribeiro afirma, para constituir o sujeito, no seu caso, uma mulher negra, é necessário criar um lugar e um estatuto, segundo as suas palavras: "definir-se a si próprio é um estatuto essencial de reforço e permite distinguir as possibilidades de transcendência da norma colonial" (2019, p. 42-43).

\footnotetext{
${ }^{5}$ CARNEIRO, A. S. Tese de doutorado: A construção do Outro como Não-Ser como fundamento do Ser, São Paulo : USP, 2005.

6 CRENSHAW, K. Demarginalizing the Intersection of Race and Sex: A Black Feminist Critique of Antidiscrimination Doctrine, Feminist Politics and Antiracist Politics. Chicago: University of Chigaco Legal Forum, 1989.
} 
Para isso, a leitura de Kilomba e de Ribeiro formam junto com as noções de epistemicídio e interseccionalidade um complemento ou, ainda, uma ferramenta que explica as práticas discursivas de poder, e mais especificamente, do racismo epistemológico e como também são organizadas (KILOMBA, 2010, p. 29).

O conceito de epistemicídio, grosso modo, é a junção da palavra episteme (saber ou conhecimento em grego) e genocídio (o assassinato coletivo de uma população inteira), ou seja, a implementação do genocídio da fala ou do conhecimento. Um fenômeno que vem ocorrendo desde o início da colonização, que considerou oportuno estabelecer as operações de cristianização e civilização como a primeira base "metodológica", sob o jugo da aniquilação das culturas e dos estilos de vida dos povos colonizados.

Ribeiro, que também estudou Simone de Beauvoir e a noção de Outro, utiliza a noção de epistemicídio - mais especificamente, um epistemicídio do Outro - para atestar que, efetivamente, a filósofa francesa abriu um caminho de compreensão sobre o Outro e o feminismo necessário para um rompimento, porém sem ampliar as questões interligadas, como a da racialização, por exemplo. Ribeiro, sobretudo, dá luz e foco a toda historiografia afrofeminista americana, na qual, é pertinente notar a menção às intelectuais feministas negras que já abordavam a interseccionalidade e que são de gerações anteriores à de Djamila Ribeiro. Nesse aspecto, a filósofa brasileira endossa o pensamento herdado das afrofeministas americanas que concebem a questão interseccional na qual a mulher negra, nesse caso, é duplamente invisibilizada: não é nem branca, nem homem, portanto ela é encarnada em um lugar hierárquico localizado em última instância.

Para tanto, Ribeiro desloca o foco sobre as bibliografias consideradas clássicas e compõe esse quadro com outras autoras, como, por exemplo, ao citar o já mencionado trabalho de tese de doutorado de Sueli Carneiro, que estudou a noção de epistemicídio e as aplicações pedagógicas em vistas de uma filosofia da educação. O sujeito negro feminino como sujeito político, é então composto dentro de uma discussão sobre os efeitos das práticas discursivas que tentam aniquilar o ser e a prática e convivência de vida, em que as situações cotidianas se referem sempre a tentativas de submissão, 
existindo como uma luta ontológica contra a prática do racismo comum. Nesse caso, devemos primeiro cuidar de nós mesmas e, mais uma vez, isso não significa nos deixarmos negar pelo que a raça é considerada em nosso inconsciente, nem em um enraizamento histórico de práticas racistas, resultantes da escravidão e da colonização.

Segundo Carneiro (2004, p. 50),

[...]o dispositivo de racialidade beneficia-se das representações construídas sobre o negro durante o período colonial no que tange aos discursos e práticas que justificaram a constituição de senhores e escravos, articulando-os e re-significando-os à luz do racialismo vigente no século XIX.

E, em seguida, a autora continua a definir a noção de epistemicídio:

Para nós, porém, o epistemicídio é, para além da anulação e desqualificação do conhecimento dos povos subjugados, um processo persistente de produção da indigência cultural: pela negação ao acesso à educação, sobretudo de qualidade; pela produção da inferiorização intelectual; pelos diferentes mecanismos de deslegitimação do negro como portador e produtor de conhecimento e de rebaixamento da capacidade cognitiva pela carência material e/ou pelo comprometimento da autoestima pelos processos de discriminação correntes no processo educativo. Isto porque não é possível desqualificar as formas de conhecimento dos povos Dominados sem desqualifica-los também, individual e coletivamente, como sujeitos cognoscentes. E, ao fazê-lo, destitui-Ihe a razão, a condição para alcançar o conhecimento "legitimo" ou legitimado. Por isso o epistemicídio fere de morte a racionalidade do subjugado ou a sequestra, mutila a capacidade de aprender, etc. (CARNEIRO, 2004, p. 97).

Nossa próxima pista analisa o conceito de interseccionalidade - que parece apropriado para evocar a constituição do sujeito negro e racializado - dado a compreensão de que o racismo não é aplicado em uma só escala, tendo também a conjunção de outras opressões: de gênero, de sexo e de classe. Dito de outra maneira, para falar das aplicações ou práticas discursivas da própria vida, convém passar para o próximo passo da obra de Grada Kilomba, resultante do conceito de interseccionalidade. 


\section{Doméstica}

Há uma corrente de pensamento afrofeminista americano que se destacou na década de 1980: Kimberley Crenshaw, bell hooks, Angela Davis, e toda uma corrente de pensamento afrofeminista americano publicaram, principalmente na teoria jurídica, escritos sobre a aplicação de certas categorias específicas à violência e ao racismo, questionando como seria possível fazer uma interpretação correta de um fato, ou de um fenômeno, sem considerá-lo exclusivamente como particular, ou torná-lo uma percepção demasiada geral da sociedade.

A ferramenta conceitual utilizada formulou uma nova compreensão chamada interseccionalidade, cuja diversidade da opressão pode ser aplicada ao mesmo tempo. Em outras palavras, uma mulher negra de um país colonizado está sujeita a múltiplas opressões: ser mulher em relação à hipersexualização e à objetificação de seu corpo, o ciúme da mulher branca, a deslealdade na "competição" da chamada vida comum: fazer amigos, encontrar um amor, ter um bom trabalho.

A interseccionalidade é, então, um instrumento, um dispositivo, uma ferramenta para compreender a violência, seja ela em termos metafísicos ou encarnados, na aplicabilidade da realidade e da lei, e que visa acrescentar uma dinâmica de dominação, mais uma vez circunscrita a um modo de vida e a uma performatividade social baseada na invisibilização do outro em uma escala hierárquica - colocando a mulher negra no último grau, duplamente invisível pelo seu gênero e pela sua condição racial.

No que diz respeito ao tema da interseccionalidade aplicada ao gênero, ao sexo e à raça, existem grandes referências que permitem uma extensão estratégica da compreensão, nomeadamente a obra-prima Sexo, Raça e Colônias ${ }^{7}$, bem como o corpus teórico de Elsa Dorlin ${ }^{8}$, ambos infelizmente sem tradução para o português. Através da genealogia histórica, essas obras afirmam um caminho de constituição do discurso

\footnotetext{
7 BLANCHARD, P., GEMEAUX, C. de « Disposer des corps : contrôler, surveiller et punir », CAMISCIOLI, E. TARAUD, C. « économie politique de la sexualité coloniale et raciale » in P. Blanchard, P. Bancel, N. Boëtsch, G. Taraud, C. Thomas, (dir), Sexe, Race \& Colonies. Paris : Editions Découverte, 2018. pp. 142-146 ; p.182.

8 DORLIN, Elsa. La matrice de la race. Généalogie sexuelle et coloniale de la nation française. Editions Découverte. 2006. Aussi : Sexe, genre et sexualités. Paris : Edition Puf, 2008. P. 23
} 
médico, jurídico e social, com provas "objetivas", como a medição de crânios e a iconografia que formalizou toda uma psicologia estético-moral, tendo o caso da categoria nomeada Vênus Hottentote ${ }^{9}$, como o mais chocante nos termos de exibição e espetacularização do corpo negro feminino.

Kilomba (2010, p. 57), que se apoia nos textos de Essed (1991) e hooks (1989), confirma que há um impacto simultâneo da opressão de raça, classe e gênero, uma vez que "O racismo, por exemplo, não funciona como uma ideologia e estrutura distintas; ele interage com outras ideologias e estruturas de dominação como o sexismo".

Uma mulher negra diante de uma situação de violência epistêmica a vivencia como um ataque múltiplo de diferentes origens: não ser mulher branca, não ser um homem, e, em último grau, não ser rica.

Acima de tudo, trata-se de reconhecer na interseccionalidade de gênero, classe e raça, nas mulheres negras e racializadas, um modo que reduz o corpo feminino ao simular a repetição de um protocolo de julgamento que primeiro liga as mulheres negras e racializadas à sexualidade excessiva, ao passar por uma assimilação entre comportamentos "sedutores" e "traços de animalidade", moralmente desumanizados, aniquilados por sua palavra e até privados de uma afirmação existencial.

Para retomar a leitura de Kilomba a este respeito, podemos citar como exemplo as muitas vezes em que ela recebeu propostas de trabalho como faxineira. Mesmo durante uma consulta médica, apesar do seu estatuto de estudante, ela recebeu um convite para "fazer parte da família durante o verão como babá e governanta para outras tarefas simples, quase invisíveis, como cozinhar e limpar..." (KILOMBA, 2010, p.54).

Finalmente, a interseccionalidade revela mais uma vez como a condição dada $a$ priori constitui estigmas sociais e a instituição aplicada diretamente ao corpo, por exemplo, a imagem de Anastácia, imagem escolhida por Kilomba (2010, p.17)como figura histórica central porque é ligada à invisibilização do escravo, reduzido a um castigo sem

\footnotetext{
${ }^{9}$ GUILHEM, D. « Une anatomie racialisée du sexe ». Sexe, Race \& Colonies. in P. Blanchard BLANCHARD, P. Bancel, N. Boëtsch, G. Taraud, C. Thomas, D. (dir), Sexe, Race \&amp; Colonies. Paris : Editions Découverte, 2018. pp. 124, 159 ; DORLIN, Elsa. La matrice de la race. Editions Découverte. Paris : 2006. p.93
} 
voz e sem boca... A máscara que segura as bocas de homens e mulheres feitos escravos ilustra que não é apenas uma origem estética da violência, mas trata-se de uma operação epistêmica. Epistemicídio como uma operação discursiva e performativa de fazer "similar" a declaração de poder de agir segundo uma brancura de dominação; como se essa fosse a única forma de comunicar ao mundo, de estar no mundo; a máscara representa um gesto performativo e se integra na definição de racismo, compõe uma imagem imediata do trauma colonial.

\section{A máscara de Anastácia}

Agora que já temos a primeira contextualização e conceituação do livro, com as noções de lugar de fala, epistemicídio e interseccionalidade, Kilomba no seu livro, propriamente dito, começa a desenvolver as suas ideias através da imagem, par excellence, que atesta a existência do racismo epistemológico aplicado à escravidão e à colonização: a máscara de Anastácia.

A máscara que silencia e que impede a boca de falar e de comer, ou seja, impeditiva do desejo, é arrebentada em cada capítulo, de maneira que ela conta uma história pessoal ou traz à luz o testemunho de uma mulher negra, que cruzado com a sua própria história, forma o black subject.

Primeiro, a aparência da máscara de Anastácia (fig. 1) é uma imagem histórica, um gesto-objeto que simboliza o silenciamento do escravo; e da boca, como uma parte do corpo humano associada ao desejo, seja de comer ou de falar. Em outras palavras, tratase de compreender o uso de uma máscara para tornar invisível a humanidade de um ou de outro. Isso permite, então, através da prática pedagógica do pensamento, que nos tornemos atores da nossa subjetividade, invertendo a lógica redutora que sempre nos vê como "o outro", o subordinado ou periférico, o simulacro do Ocidente, ou mesmo o deficiente. Kilomba (2010, p. 12), portanto, faz uma crítica: 
descritivo de minha própria história, e não o descrito (...) eu me torno o narrador, e o escritor de minha própria realidade, o autor e a autoridade sobre minha própria história. Neste sentido, torno-me a oposição absoluta daquilo que o projeto colonial predeterminou.

Figura 1 - Mascara de Anastácia

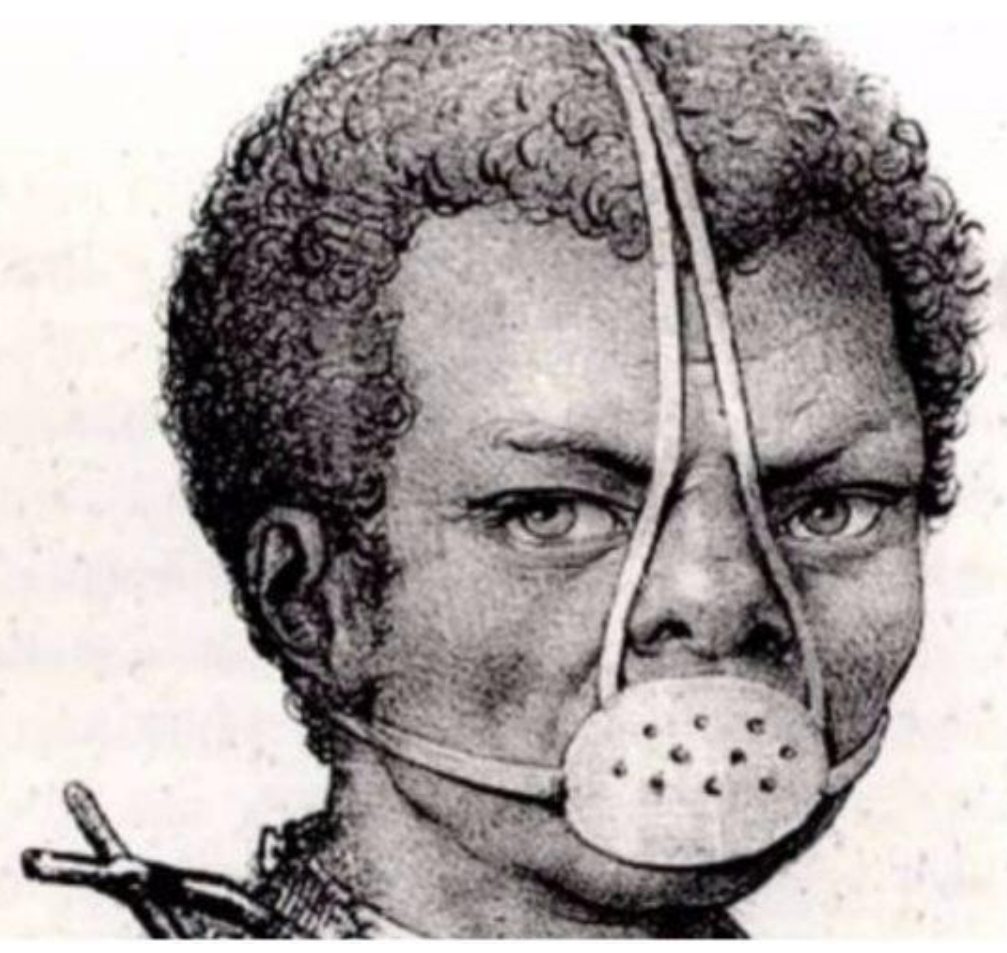

Fonte: Kilomba, 2010, p. 17.

A autora, através de narrativas pessoais e conceituais, decifra a emergência de uma consciência crítica ao racismo ontológico no pensamento ocidental, ou seja, é um texto que propõe estudar as operações discursivo-performativas do racismo, a partir de sua aplicabilidade discursiva do poder.

Muito provavelmente nos repetimos nos mesmos termos semânticos, porém sua potência significante e sua aplicabilidade discursiva sobre o sujeito, torna também possível pensar os mecanismos do Ego, enquanto psique responsável pelo inconsciente ou por aquilo que não temos controle, afetivo ou emocional, nos resultados cotidianos. 
Quando lemos Kilomba, em âmbito pessoal e acadêmico, observamos as operações, que aqui mostraremos lado a lado para melhor comparar as diferenças e as possibilidades de enredo do sujeito; e o combate narrativo entre a resistência e a criação do sujeito Negro e racializado no contexto do racismo ontológico-epistemológicoestético-subjetivo-afetivo.

Neste texto, a comparação é realizada de maneira introdutória, no entanto nos parece pertinente revelar o que pretendemos compreender sobre o significado do racismo, nas manifestações acima reveladas e nos âmbitos institucional, político e cotidiano. Assim, para escrever este artigo a partir de uma leitura kilombiana feita de maneira correta, precisamos localizar nestes mecanismos de defesa uma concreta teoriaprática do pensamento, que é também performativo, a fim de que se efetive uma reparação histórica e subjetiva.

Nisso, a autora propõe no seu trabalho como psicanalista, cinco mecanismos de defesa do Ego (Gilroy 1987, 1992, apud Kilomba, 2010, p. 22-23). Primeiro, trataremos aqui, os cinco mecanismos de defesa da negritude, cada qual correspondente a um rol de afetos e relações, ditos de outra maneira, de procedimentos psíquicos.

\section{Cinco mecanismos de defesa da Negritude}

O passo a seguir é fazer uma apresentação dos mecanismos de defesa da Negritude, sabendo que Kilomba, antes de apresentá-los desenvolve, quanto à noção de trauma, uma consequência externa à violência do racismo; portanto, antes de se defender concretamente, é preciso compreender como opera o trauma do racismo. Kilomba afirma que na etimologia grega, trauma significa uma "ferida" ou uma "lesão" o qual cita Freud como aquele que acima de tudo forma uma teoria do esquecimento do trauma (2010, p. 132).

\footnotetext{
${ }^{10} \mathrm{O}$ título original é "Black subject"; preferi o uso do termo "Negritude", mas ainda não tive acesso à edição portuguesa, portanto não sei qual termo Grada Kilomba escolheu para a tradução em português.
} 
Para resolver esse problema, Kilomba (2010), conta com Fanon (1967) e Bouson (2000) porque, antes de tudo, trata-se de uma contínua ferida colonial, que revive a cada momento o trauma do racismo, da escravidão, tal qual uma teoria da reminiscência. Haja vista que a supremacia branca sempre nos recorda da violência e do terror, entre as três descrições de racismo já discutidas: a criação do Outro como o diferente, a inferioridade moral e o poder de ação. Em vez do esquecimento originário do inconsciente, trata-se de uma questão da memória, e como o trauma persiste na psique do sujeito.

São três sintomas citados específicos do trauma colonial: o choque violento, por exemplo, o toque dos cabelos, a questão do "ser europeu e alemão" (ou "americano", eu diria aqui), o imediatismo do racismo colocado na imagem do que se é. A segunda é a separação, quando a personalidade se afasta do sujeito, é a negação do desejo, da vontade de se expressar, seguida pelo silenciamento e pela invisibilização. A terceira é reviver uma situação do passado, como a história da escravatura e o passado colonial de repressão e exclusão, diria eu, de um passado recente.

No que diz respeito à descolonização, o movimento de deixar de operar segundo uma psique inconsciente ou colonial, Kilomba cultiva a sua teoria performativa no subtítulo do livro: episódios do racismo cotidiano. A par de algumas das fantasias coloniais que persistiram até os dias de hoje, isso é particularmente evidente na relação com um público branco, ela analisa isso fazendo três abordagens (KILOMBA, 2010, p. 138 140), entre as quais está "cuidar" ou tomar "consciência", seja da acusação de vitimização, seja da dependência da aprovação ou, ainda, do perfeccionismo de "superioridade" (KILOMBA, 2010, p. 139): "O mito dos negros que se vitimizam quando falam das feridas causadas pelo racismo é uma estratégia muito eficaz para silenciar aqueles que estão dispostos a falar".

É, sobretudo, por um empoderamento que nos permite agir e viver, criar nossos sujeitos existenciais e afirmar-nos como tal, sem o medo de reviver ou repetir o trauma. Ela continua: "A pergunta é direta ao interior (o que se fez com você) e não ao exterior (o que você fez - com eles). Isso é para mim bastante revolucionário [...]. O racismo não é uma falta de informação, mas sim um desejo violento de possuir e controlar o sujeito negro". (2010, p. 139). 
Kathleen, um dos testemunhos citados por Kilomba (2010, p. 145), admite que seu único desejo era ser compreendida, nem como uma mulher maravilha nem como um ser sub-humano. Dito de outra maneira, não se trata de repetir fórmulas brancas de excelência, sempre com uma hierarquia de valores e posições sociais arraigadas.

Para sair desse estado de constante competição e concorrência, Kilomba (2010, p.143) finaliza com cinco mecanismos de defesa do ego Negro que permitem sair da servidão da perfeição branca, em que ela afirma: “Essa fantasia da perfeição, no entanto, não é realmente gratificante. Ela leva a um estado constante de decepção. [...] Além disso, essa fantasia cultiva a ideia de servidão".

Do lado racializado e negro, há uma série de discussões sobre os traumas relativos consequentes do meio social: a negação de si de quem não é branco, que consiste na afirmação e na recusa de ser e de existir enquanto negro e racializado, o que conduz ao desenvolvimento de uma dependência de aceitação constante que reina nos meios colonizadores e colonizados. Observamos igualmente a aceitação do racismo através de uma hierarquia dos seres: em primeiro lugar o homem branco, depois a mulher branca, seguida pelo homem negro e, em último lugar a mulher negra, refletindo mais uma vez a interseccionalidade das opressões.

Seguindo Kilomba (2010, p. 144), para sair e se descolonizar dessa condição desumanizadora, os cinco mecanismos de defesa do ego do sujeito Negro (Black subject) são: negação, frustração, ambivalência, identificação e descolonização.

O primeiro é a negação, mencionada no parágrafo acima e como efeito imediato do racismo, pura e simplesmente a negação de si, da sua existência enquanto tal e a contínua performatividade de cópia e simulacro para ser aceito nos meios sociais e institucionais. Segundo Kilomba (2010, p. 144): "como mencionado anteriormente, é o mecanismo de defesa do ego no qual uma experiência só é admitida ao consciente nesta forma negativa".

Porque causa tanta ansiedade admitir que a negação protege e antecipa, ela é feita através de outras negações: "Eu nunca tive experiência com racismo"; "Eu não sou realmente negro" ou "Eu não sou tratado de forma diferente", são frases ditas com certa 
frequência. Inclusive fazendo uso de palavras do repertório de linguagem do opressor, direcionado ao "Outro" branco: "Isto não é racismo"; "Eu não quero me definir como negro, porque somos todos humanos"; "Eu acredito que em nossa sociedade não há diferença”.

O segundo mecanismo de defesa do ego é a frustração, consequência dessa tomada de consciência, quando nos vemos diante de uma realidade de privilégios a qual não temos o mesmo acesso. Nas palavras de Kilomba (2010, p. 144):

Frustração é o estado de ser, ou ter sido, diminuído, desconcertado ou desapontado. (...) Frustração refere-se, portanto, à falta de oportunidades necessárias para a satisfação, o sujeito negro está insatisfeito porque ele / ela não tem as mesmas oportunidades que o senso comum branco. Frustra-se com o outro branco e a sociedade branca em geral. A sequência de frustração é - agressão - ansiedade defesa e - inibição.

Consequentemente, o terceiro mecanismo de defesa se refere à coexistência ou à ambivalência de sentimentos e afetos, como o amor e o ódio. Ambivalência não significa que se tenha misturado um sobre o outro, mas sim que haja uma atitude emocional subjacente na qual as opiniões contraditórias derivam da mesma fonte.

Sente-se raiva e culpa pelos brancos, repugnância e esperança, confiança e desconfiança. Orgulho e culpa para com os negros, solidariedade e vergonha, confiança e dúvida: dois sentimentos contraditórios em relação a um único objeto. Essa etapa é uma preparação para o quarto mecanismo de defesa, que é o da identificação: com quem devo me identificar?

A identificação refere-se ao processo em que o sujeito dá origem ao quinto e último mecanismo de defesa, que é a descolonização em que,

Assimila um aspecto do outro e é transformado, total ou parcialmente, depois que o outro fornece (Laplanche e Pontalis 1988:205). Nesse estado, o sujeito negro inicia uma série de identificações consecutivas com outros negros: sua história, suas biografias, suas experiências, seus 
conhecimentos, etc. Tal processo conduz à reparação e abertura em relação aos brancos, uma vez que a interioridade está fora da ordem colonial. Todo o processo atinge um estado de descolonização, isto é, internamente já não existe como o "Outro", mas como o eu. Um é o eu, um é o sujeito, um é o descritivo, o autor e a autoridade sobre a própria realidade. Quando eu comecei este livro: um se torna o sujeito. (KILOMBA, 2010, p. 144).

\section{Os cinco mecanismos de defesa da branquitude}

Uma vez que analisamos os mecanismos de defesa da negritude, fazemos a composição da leitura de Grada Kilomba sobre os cinco mecanismos de defesa do ego da branquitude. Vale notar que Kilomba também ilustra esses mecanismos de defesa da branquitude em sua obra exposta na Pinacoteca de São Paulo, denominada The Dictionary; onde apresenta a sua versão dos cinco mecanismos: negação, culpa, vergonha, reconhecimento e reparação.

O primeiro é a negação, que consiste em "um mecanismo de defesa do Ego no qual opera inconscientemente para resolver um conflito emocional, recusando a admitir os aspectos desagradáveis da realidade exterior, o conhecimento interior ou as intuições" (KILOMBA, 2010, p. 22). Nesse caso, Kilomba menciona o fato de colocar sobre o(s) Outro(s) a responsabilidade do racismo, negando a si mesmo a afirmação "nós somos racistas" à uma resposta: "eles são racistas" ou, o que nos capítulos posteriores Kilomba comenta, a contra-acusação da "vitimização".

Em seguida, o segundo mecanismo de defesa do ego é a culpa, segundo Kilomba (2010, p. 22), ela é:

A emoção que se segue à violação de uma injunção moral. [...] É um estado afetivo em que se experimenta o conflito por ter feito algo que se acredita que não se deveria ter feito, ou ao contrário, por não ter feito algo que se acredita que se deveria ter feito. Freud descreve isso como o resultado de um conflito entre o ego e o superego, ou seja, um conflito entre os próprios desejos agressivos da pessoa em relação aos outros e o superego (autoridade). 
Acusação, vergonha e punição são algumas das consequências, diferindo da ansiedade, a resposta do senso comum para a culpa é a intelectualização ou racionalização do assunto sobre o racismo, de maneira que há uma tentativa de justificar o racismo ou dar uma resposta que pressupõe um mal-entendido...

O terceiro mecanismo de defesa do ego é a vergonha, resultado do conflito entre o poder que os privilégios da branquitude the conferem e o alarme desta disparidade, o medo do ridículo e a resposta a uma falha de viver seguindo um "ego ideal" (KILOMBA, 2010, p. 22).

Sendo assim, Kilomba (2010, p. 22) define este mecanismo em que;

O sujeito da branquitude compreende que a percepção que os negros têm da branquitude pode ser diferente da sua própria auto-percepção, pois a branquitude é vista como uma identidade privilegiada, o que significa tanto poder como alarme - a vergonha é o resultado deste conflito.

Como veremos a seguir, Kilomba ilustra estes cinco mecanismos de defesa do ego na sua obra audiovisual Narcissus and Echo, tendo como o passo seguinte 0 reconhecimento e a reparação, saindo do pacto nassico da branquitude, termo cunhado na tese de doutorado de Maria Aparecida Bento. Fundamentais para que a sociedade, ocidental ou não, possa reconstituir sua história, dar oportunidades psicossociais e, finalmente, empoderar o sujeito na sua diferença. Conforme a autora:

O reconhecimento segue-se à vergonha; é o momento em que o sujeito branco reconhece a sua própria branquitude e/ou racismos. É, portanto, um processo de reconhecimento. Finalmente se reconhece a realidade aceitando a realidade e a percepção dos outros. O reconhecimento é, neste sentido, a passagem da fantasia à realidade - não se trata mais de como eu gostaria de ser visto, mas sim de quem eu sou; não o que eu gostaria que fossem os 'Outros', mas quem eles realmente são. (KILOMBA, 2010, p. 22-23). 
Reparação significa a negociação do reconhecimento. Negocia-se a realidade. Nesse sentido, é o ato de reparar o dano causado pelo racismo ao mudar estruturas, agendas, espaços, posições, dinâmicas, relações subjetivas, vocabulário, isto é, abdicar de privilégios. Esses diferentes passos revelam a consciência do racismo não tanto como uma questão moral, mas sim como um processo psicológico que exige trabalho. Assim, em vez de fazer a pergunta moral comum: "Sou racista?" e esperar uma resposta confortável, o sujeito branco deveria antes perguntar: "Como posso desmantelar o meu próprio racismo?"

\section{Narcissus and Echo}

A obra de arte visual Illusions 1: Narcissu and Echo está representada em dois elementos: o primeiro é o uso de motivos gregos para reformulá-los e lhes dar uma nova linguagem, desta vez reparados e curados do trauma colonial da escravidão, e o segundo é a encenação da palavra como modo de narrar a vida, uma transmissão de conhecimento e sabedoria, contando uma história com a mesma "magia" da sensibilidade, pode-se dizer, humana, artística. Kilomba muitas vezes fala da influência Griô sobre o seu repertório e sua maneira de contar uma história, equivalente aos antepassados e a transmissão de saberes, ancestrais e contemporâneos.

Na sua exposição na $32^{\mathrm{a}}$ Bienal de São Paulo e, mais recentemente, na Pinacoteca de São Paulo, ela explica que a série Illusions e, mais especificamente, Narcissus and Echo refletem motivos gregos para ilustrar a sociedade contemporânea, o racismo institucionalizado - aqui também lido como racismo ontológico. Não é uma questão de provar "ignorância" ou "falta de conhecimento", mas de demonstrar que o poder é usado para evitar até mesmo a necessidade de aquisição de conhecimento (saber) ou simplesmente ignorá-lo. É dada pela constante reformulação da reescrita do passado, uma reformulação de si próprio em categorias racistas ou econômicas.

A figura de Narciso torna-se, portanto, uma figura que não vê só a si mesma, e na peça de Grada Kilomba os personagens estão inseridos em um cubo branco, como uma forma sensível de ataque ao inconsciente colonial e colonizado. 
Soma-se a isso, segundo o relato de Kilomba, a relação temporal de Narciso, que é não pensar no futuro e permanecer sempre em um passado vivido, como se fosse alimentado por uma fantasia ou uma virtualidade desvinculada da realidade.

Depois, para a composição coreográfica, Kilomba (2016) conta numa entrevista ${ }^{11}$ que se tratava de uma questão de ritmo, em uma ambiguidade mágica, tal como o canto de Nina Simone. Dessa forma, o sujeito fica preso na magia, seja ele qual for, aquela que não quer ver a realidade, e no caso colonial, que se reduz à escolha de uma única imagem, aquela que é a sua, e todas as outras não existem, isso é narcisismo.

Nas palavras de Kilomba (2016) $)^{12}$, "ele, o Narciso, embora saiba tudo, decide não querer saber e reduz tudo à sua imagem, como privilégio de não querer saber que reflete continuamente imagens coloniais". Devemos, portanto, reformular sua "primeira" influência, sem esquecer o Narciso, retomar o Narciso e assim dar um novo e reparado corpo a esta história.

O que Kilomba garante, desta forma, é que todos nós podemos cair em mitos e fetiches. Ela, portanto, usa o mito do Narciso para compreender outros mitos, como o da supremacia branca. A narrativa ficcional e pessoal de Kilomba propõe, de acordo com as muitas vezes que a vi falar, um convite à procura do conhecimento, a não negligenciar que se estudarmos, se praticarmos uma pedagogia emancipatória crítica das injustiças sociais $^{13}$, podemos constituir sujeitos e novas aplicações das palavras, como faz Kilomba: íntima e ética. Sem pretensão de se tornarem definitivos, todos esses caminhos são apenas uma amostra exemplar da riqueza bibliográfica que visa renovar ou reviver as epistemologias do Sul ${ }^{14}$.

\footnotetext{
${ }^{11}$ Entrevista concedida à Mariana Tessitore em vídeo sobre a exposição na Pinacoteca de São Paulo, Grada Kilomba, vídeo 2019 (Acessado em 2019:_https://vimeo.com/325388160).

${ }^{12}$ Idem. Transcrição.

${ }^{13}$ HOOKS, bell. Teaching to Transgress: Education as the Practice of Freedom. New York: Routledge. 1994. Teaching Community: A Pedagogy of Hope. New York: Routledge, 2003.

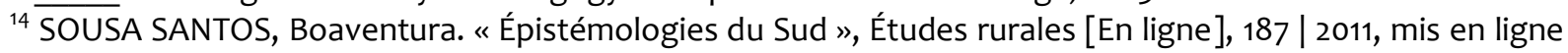
le 12 septembre 2018, (Acessado em 01 setembro 2019. URL: http://journals.openedition.org/etudesrurales/9351; DOI : 10.400o/etudesrurales.9351).
} 
Fig.2 e 3 - Grada Kilomba, série Illusions, vol II: Narcissus and Echo, 2019
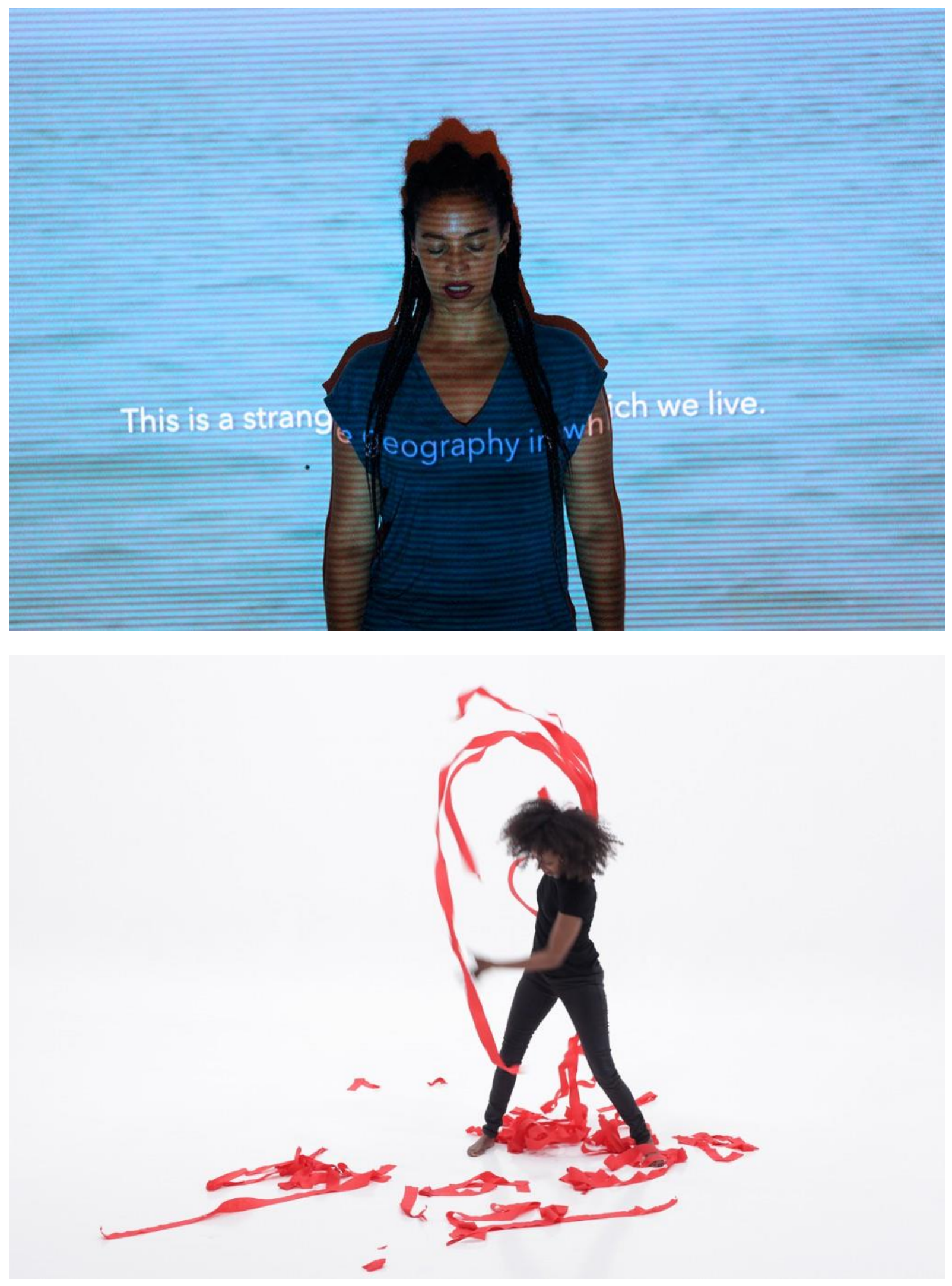

Fonte: Kilomba, Gorki Theater, 2019. 


\section{Carta à Grada Kilomba}

Quando te vi em Paris, na tua presença, o que eu senti foi uma força guerreira de lansã. E de repente, é assim o jeito de elogiar as pessoas e os projetos políticos aportados por elas, as suas vozes, os seus direitos de existência, te comparo à lansã porque é de cosmogonia (origem do mundo) que estamos falando, que sejam arquétipos ou outras palavras difíceis, o que sei é que senti uma potência e me basta.

Te pergunto, querida Grada, como então adquirir uma voz que seja também formar um sujeito?

Estamos desde esse sempre em luta de existência, sabe deus quantas vezes fui julgada de doida, doidinha, puta, vadia e, mesmo esse texto sabe-se lá o que vão pensar... mas também fé cega, faca amolada, porque com os nossos (deuses) não se perdoa a injustiça, se age no ato, com corpo e afeto. Provocando e sendo mais direta, não ficam moralizando, dizendo ou vai pro inferno ou vai pro céu, de repente é daí a enorme concentração sobre o passado, a branquitude ainda não saiu da chantagem do certo e errado. Se eu posso me incluir no que penso de ti e desse projeto político chamado descolonização do sujeito, é que sou testemunha desta emancipação e render homenagens é mais do que necessário, é humano mostrar que somos exemplos de exemplos e assim fazemos comunas mais locais, mais humanizadas, mais particulares...

De repente, a essência do humano é a liberdade, ou ainda, uma representação dela. Tudo no humano é linguagem. Verdade ou falsidade são dispositivos de poder, de agir, de ser e estar. Mas também podem ser expressões parresia de sincera honestidade ou inocência, de querer o bem para todos. Tu, Grada Kilomba, renova os sentidos do amor político de Bell Hooks, mestra Griô, par excellence, cria espaços seguros éticos e engajados, nos permite acreditar em polis ou o sentido mesmo de comunidade, com a potência cosmogônica africana e o bem-querer de um sábio. O saber decolonial.

É importante que esse texto também possa ser lido como um exemplário, qui guia, qui organiza, qui se manifesta, qui aponta, mas que não é hierárquico, por isso e por tantas outras questões a descolonização importa, ainda que a violência e o trauma colonial estejam aqui, no nosso corpo. 
Hoje é sexta-feira e é dia de Oxalá, meu pai; estou de branco em sua homenagem, é ele quem me dedica este escrito uma força forma de ser/estar. Na verdade, peço perdão porque explicando aos brancos simplifico para fazer tentar entender no peito.

Me lembro que quando nos vimos eu te agradeci de peito aberto, e uma vez mais, Grada, obrigada. Ora, ao meu ver, o que eu senti veio de uma mestra Griô ${ }^{15}$ e eu só tenho a agradecer.

Axé!

\section{Referências}

CARNEIRO, Aparecida Sueli. A construção do outro como não ser como fundamento do ser. Tese (doutorado em Educação) - Faculdade de educação, Universidade de São Paulo. São Paulo. 2005

KILOMBA, Grada. ArteBrasileiros - Performance "ILLUSIONS VOL. I, NARCISSUS AND ECHO” de Grada Kilomba 32. Bienal de São Paulo (2016). [Entrevista cedida a] Mariana Tessitore. ARTE!TV, nov. 2016. Disponível em: https://vimeo.com/325388160. Acesso em: mar. 2019.

. Plantations Memories: episodes of everyday racism. Berlin: Unrast, 2010.

RIBEIRO, Djamila. Lugar de Fala. Polen, São Paulo. 2019.

Recebido em: 05/10/2019

Aprovado em: 19/12/2019

Universidade do Estado de Santa Catarina - UDESC

Centro de Ciências Humanas e da Educação - FAED

Revista PerCursos

Volume 20 - Número 44 - Ano 2019

revistapercursos@gmail.com

\footnotetext{
${ }^{15}$ Mestre A. Lima, A. C. Costa. Dos griots aos Griôs_a importância da oralidade para as tradições de matrizes africanas e indígenas no Brasil. In: Pedagogias Griô. Revista Diversitas, Ano 2, set. 2014/mar. 2015.
} 